\title{
Erratum zu: Akut-Tagesklinik als kosteneffiziente Alternative zu stationärer Therapie
}

\author{
Kunigunde Pausch · Carlos Nordt · Eva-Maria Pichler · Ingeborg Warnke · Erich Seifritz · Wolfram Kawohl
}

Online publiziert: 7. April 2017

(C) Springer-Verlag Wien 2017

\section{Erratum zu:}

Neuropsychiatr

DOI 10.1007/s40211-017-0221-6

Der Originalbeitrag wurde korrigiert. Leider wurde im Bildbearbeitungsprozess Abb. 1 falsch bearbeitet und gedruckt. Korrekt ist die hier dargestellte Abbildung.

Interessenkonflikt K. Pausch, C. Nordt, E.-M. Pichler, I. Warnke, E. Seifritz und W. Kawohl geben an, dass kein Interessenkonflikt besteht.

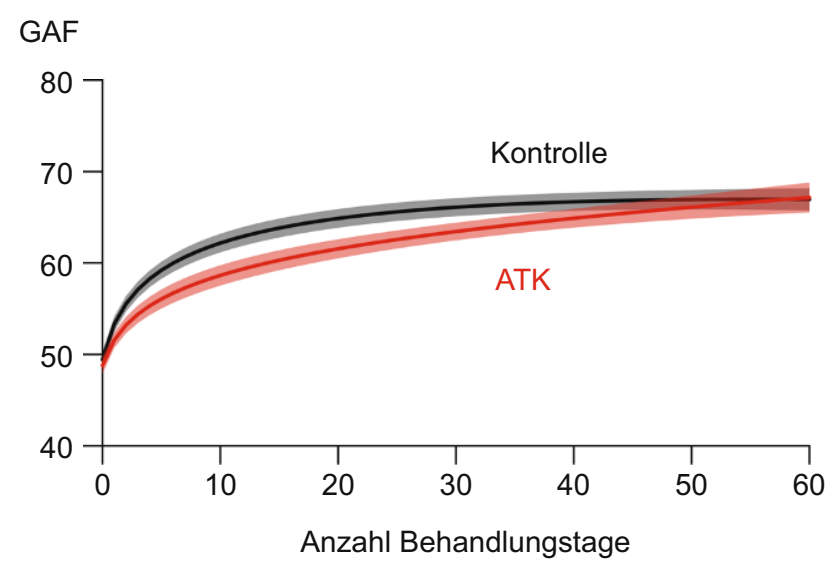

Abb. 1 Global Assessment of Functioning (GAF)-WertEntwicklung in Bezug auf die Anzahl der Behandlungstage bei der Kontroll- und ATK-Gruppe

Die Online-Version des Originalartikels ist unter doi: 10. 1007/s40211-017-0221-6 zu finden.

Dr. med. K. Pausch $(\bowtie) \cdot$ C. Nordt · E.-M. Pichler $\cdot$ I. Warnke

E. Seifritz · W. Kawohl

Klinik für Psychiatrie, Psychotherapie und,

Psychosomatik/Zentrum für Soziale Psychiatrie,

Psychiatrische Universitätsklinik Zürich,

Militärstrasse 8, 8021 Zürich, Schweiz

kunigunde.pausch@puk.zh.ch 